\title{
Research on Gossip: Taxonomy, Methods, and Future Directions
}

\author{
Eric K. Foster \\ University of Pennsylvania
}

\begin{abstract}
A half century of gossip research from multiple disciplines is reviewed. Discussed are definitions of the construct; social, evolutionary, and personal functions of the practice; and data collection methods. Though people engage in the practice frequently, there has been relatively little psychological research on gossip. The layperson's understanding of the term is included in, but insufficient to encompass, definitions used by researchers. Most data are ethnographic and discursive, and few parametric data exist. The area could benefit from better experimental methods and instruments. Neurobiological and social network analysis methods are promising foundations for further study. There are real-world implications for understanding gossip. Strengthening gossip theory and research methods will beneficially inform the way we view the practice in context.
\end{abstract}

Virtually all of us frequently find ourselves producing, hearing, or otherwise participating in evaluative comments about someone who is not present in the conversation. It is often valuable (and sometimes unavoidable) to be part of such communications. To function efficiently in a complex social environment, humans require information about those around them. But social interconnections are complex, and it is impossible to be present at many primary exchanges to absorb this kind of information directly. Thus, many people are eager to pick it up through an intermediary, whether or not they have the luxury and patience to confirm it later either directly or indirectly. This phenomenon, of course, is called gossip. It is an important social behavior that nearly everyone experiences, contributes to, and presumably intuitively understands. The purpose of this article is to review and summarize research on this phenomenon and point to some promising ways to study it going forward.

A paradox of gossip is that it is ubiquitous, though there are numerous social sanctions against it. Anthropologists and others have documented its practice the world over (Besnier, 1989; Gluckman, 1963; Haviland, 1977; Levin \& Arluke, 1985; Loudon, 1961; Stirling, 1956).

Eric K. Foster, Marketing Department, The Wharton School of Business, University of Pennsylvania.

Correspondence concerning this article should be addressed to Eric K. Foster, 191 Presidential Boulevard PH6, Bala, PA 19004. E-mail: efoster@netaxs.com
Indeed, social anthropology is sometimes said to be the social science of gossip. Yet, gossip (and rumor, which differs primarily by always being speculative and sometimes pertaining to events rather than people) has been denounced from antiquity to the present. Most societies have explicit sanctions against gossip, and numerous cautionary narratives demonstrate its unwanted outcomes. "Whoever repeats gossip lacks understanding" is the admonition in Ecclesiastes. "Be not a tale bearer," Leviticus cautions. "Don't gossip," parents and teachers simply warn children. Nevertheless, unless a conversationalist specifically draws attention to the fact that gossiping is occurring, it is likely to proceed relatively unhindered (Yerkovich, 1977). Obviously, for gossiping and the sanctions against it to coexist, there must be value in the generation and consumption of gossip that outweighs the counterforce of the sanctions.

There is no denying that gossip, like rumor, "can steal illusions, wreck relationships, and stir up a cauldron of trouble" (Rosnow, 2001, p. 203). Targets may be hurt by seeing how others perceive their affairs, by distortion or manipulation of information, or by the violation of private matters. Many ethical condemnations of gossip revolve around presumed rules of privacy. Bok (1983), for instance, sees gossip unequivocally as morally indefensible because of this violation. A relevant historical trivium: The dumbwaiter was invented so that servants could not overhear the most private familial and business affairs of their employers over dinner and then "retail their masters' business" (Hecht, 
1956, cited in Goffman, 1959, p. 213). Misinformation is also at the heart of condemnations of gossip. Harrington and Bielby (1995), for instance, in their study of the effects of electronic bulletin boards (precursors of Internet chat rooms) on facets of gossip, discovered that online discussions contain a greater demand for explicit referencing of verifiable sources. These sources would compensate for the lack of other confirmatory indicators, such as status, expertise, interpersonal connections, direct access to information, and so forth, that are generally more available in face-to-face conversations with known players. Ayim (1994) also portrayed gossipers as intent on establishing the veracity of gossip, although Blumberg (1972) remarked that extensive monitoring of gossip over time is unlikely and impractical. In either case, the inclination to gossip covertly, anonymously, or vicariously betrays an awareness of the violation of privacy norms. Generally, people seek to guard themselves against the charge of indiscretion when gossiping.

An interesting counterpoint to the gossipviolates-privacy charge was articulated by Schoeman (1994). He argued that gossip, far from violating privacy, is in fact consistent with privacy norms because it attenuates direct and public conflict. People usually know they are being (or will be) talked about when deviating from norms: "We all fully expect to be discussed by others who know us, with no sense of impropriety" (Schoeman, 1994, p. 80), even if we prefer not to be. Gossip provides the offended with a subtle way to pressure the offender. A public figure, for instance, may capitulate to gossip for a transgression, yet be relieved that the affair did not "get into the papers." (In the case of positive gossip about a person, the gossiper is spared being obsequious while buoying the target's reputation with a "third-party endorsement.") Blumberg (1972), finding strong evidence that evaluations traveling through the network tend to stop short of their targets, concluded that a norm seems to exist "to keep people from learning too much about what others think of them" (p. 161). Wert and Salovey (2004), in this issue, also acknowledge that gossip affords one the benefits of various veins of social comparison while avoiding the risks of embarrassment or confrontation. Thus, gossip, far from violating privacy, may be construed as a protective social norm. It is less bruising when originating from people more socially distant from the target and less likely to be practiced by those closer to the target (who, as in the case of family members, might be expected to be more direct in their communications).

How much do people gossip? Apart from obvious individual differences, the answer depends greatly on how the term is defined. Dunbar, Marriott, and Duncan (1997) sampled 45 conversations every $30 \mathrm{~s}$ while eavesdropping in public. They found that "social topics" concerning either those persons present or third parties were the purpose of conversation about two thirds of the time among both men and women. Only a small proportion (less than 5\%) of this conversational time was spent in critical remarks about third parties (i.e., malicious gossip in the colloquial sense). Similarly, defining gossip as Dunbar et al. (1997) did, Emler (1994) reported that about $70 \%$ of conversation time involved gossip.

Both of these estimates would certainly diminish, however, if only social remarks about people not present were the criterion. In an earlier article, Emler (1990), limiting his definition to gossip about absent persons, found that named acquaintances were still the most common topic of conversation after self-disclosure. Slade (1997) distinguished five types of informal conversation and reported that about one seventh $(14 \%)$ of the time spent in workplace coffee-break conversation consisted of gossip. However, because she limited her definition to negative gossip, the percentage would presumably be higher with positive remarks included. There is little empirical evidence that women gossip more frequently than men (cf. Dunbar, 1993a, 1994; Eckert, 1990; Foster, 2003; Haviland, 1977; Levin \& Arluke, 1985; Loudon, 1961; Nevo, Nevo, \& Derech-Zehavi, 1993); in general, any reported differences between the sexes are small.

Thus, with current data, it is not easy to get a precise fix on the amount of time that people spend gossiping. Nevertheless, it is reasonable to conclude that most people spend a nontrivial portion of their interpersonal time gossiping. Indeed, several writers have remarked that not to gossip (or not to respond to gossipy overtures with at least a modicum of interest) is to be quickly marginalized from the local social fabric (Bergmann, 1993; Eggins \& Slade, 1997; 
Gluckman, 1963). On the other hand, a reputation for too much gossip may also marginalize a person (Bergmann, 1993; Gilmore, 1978; Yerkovich, 1977), perhaps because the security of information passed to such a person is not assured, and the value of information learned from him or her is questionable. Confining the domain to the workplace, Kurland and Pelled (2000) postulated a curvilinear relationship whereby too much or too little gossiping may adversely affect one's referent (attractional) power. None of these authors presented empirical evidence for these relationships, however.

Psychology researchers have largely overlooked gossip. The volume of work on the topic is scant both in journals and, particularly, in textbooks. I have located only a single psychology textbook with gossip in the index (two pages on the topic, in passing). Nor is it listed in the cumulative subject index of recent editions of the venerable Handbook of Social Psychology (Gilbert, Fiske, \& Lindzey, 1998; Lindzey \& Aronson, 1970, 1985). The number of journal articles has remained thin over the last 40 years as well. I gleaned references to the topic in PsycINFO, ERIC, and JSTOR since 1970 using the single keyword gossip; results are shown in Figure 1. The frequencies observed are quite small relative to any other activity that takes up so much of our daily interpersonal communications. Nor, according to a Web search of "gossip and syllabus," is gossip a topic typically included in classroom materials (Table 1), although psychology students certainly seem fascinated when it is broached in class.

\section{Defining the Gossip Construct}

This special issue is testament to the fact that gossip does not lend itself to simple formulaic definitions or uniform explanations. We all "know" what gossip is, but defining, identifying, and measuring it is a complex enterprise for practical investigation. At the very least, the everyday understanding of the term gossip is included in, but insufficient to encompass, the construct as used by researchers. Defining the content, circumstances, and functions of gossip will help to put the research methods used to study it into perspective.

At the most general level, gossip behavior includes "idle talk" or "chit chat" about daily life. Dunbar (2004), in this issue, defines it broadly as conversation about social and personal topics. In some feminist criticism, gossip is nearly synonymous with "women's talk" in general (E. B. Brown, 1990; Coates, 1988; Eggins \& Slade, 1997; Jones, 1980; Spacks, 1982) or "girl talk" (Eckert, 1990). Rysman (1977) traced the etymology of the term as it refers specifically to women. The parallels in men's conversation-"shop talk," "shooting the

\section{Number of Articles with Keyword Gossip in Abstract}

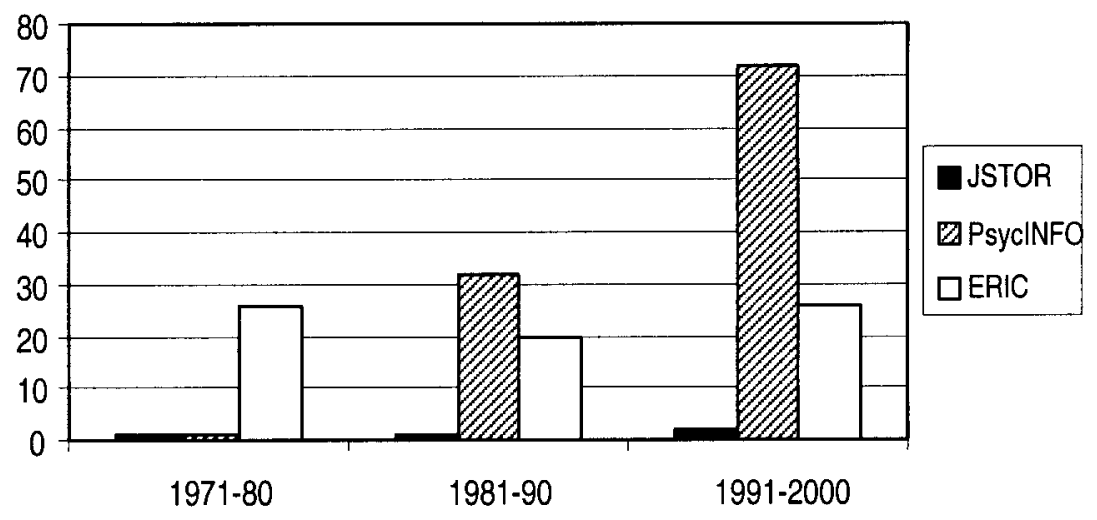

Figure 1. Electronic searches for articles related to gossip, 1971-2000. JSTOR subject areas available were anthropology, education, and sociology; 37 journals were searched in JSTOR, including Social Psychology, Social Psychology Quarterly, Annual Review of Sociology, and Annual Review of Anthropology. 
Table 1

Internet Searches for Syllabi on Topics Related to Gossip

\begin{tabular}{lccc}
\hline \multirow{2}{*}{\multicolumn{1}{c}{ Syllabus type }} & \multicolumn{3}{c}{ Approximate frequency } \\
\cline { 2 - 4 } & November 2001 & February 2004 & Increase (\%) \\
\hline Social learning & 181,000 & 699,000 & 286 \\
Networking & 40,800 & 122,000 & 199 \\
Interpersonal process & 20,000 & 44,400 & 122 \\
Conversation style & 16,000 & 30,600 & 91 \\
Social reputation & 10,700 & 23,800 & 122 \\
Interpersonal relations & 8,600 & 19,900 & 131 \\
Interpersonal communications & 8,300 & 18,500 & 123 \\
Personality style theory & 6,800 & 27,000 & 297 \\
Gossip or gossiping & 3,000 & 5,770 & 92 \\
Rumor & 1,800 & 3,240 & 80 \\
Grapevine & 1,300 & 2,760 & 112 \\
\hline
\end{tabular}

Note. These searches consisted of the topic words listed here plus the word syllabus. The content of many of the hits is far off base, so the absolute numbers shown are no doubt greatly inflated from a research point of view. Relatively, however, the numbers are reliable, because they are roughly replicable from different sources, and their ranks changed little over the 27 -month period. The point here is to show that syllabi referring to gossip consistently occur on the low end in a list of related social exchange and interpersonal communication topics and continue to grow relatively slowly.

breeze" (Fine \& Rosnow, 1978), or "killing some time together"-are essentially interchangeable with what is being referred to as gossip when it is defined so generally as idle or social conversation.

\section{Third Parties Not Present}

More typically, most people would agree that whatever is included in the content of gossip, the label is justified primarily by the exchange of information about absent third parties, in accord with the popular meaning of the term. Most of us know what happens to a gossipy conversation when the target (or a relative or close associate of the target as his or her proxy) enters within earshot (Bergmann, 1993; Yerkovich, 1977). Besnier (1989) wrote that talk about absent persons is enough to justify the label gossip. Hannerz (1967) used as his working definition of gossip the private transmission between "A and B talking about C" (p. 36). So the absence of the third party seems to be a minimal and, for many, sufficient requirement.

There are, to be sure, exceptions even to this simple rule. Gluckman (1963) noted that gossip is sometimes (but only rarely) face to face with the target. Children have been found to gossip in the presence of their target (Goodwin, 1982), and both Roy (1958) and Handelman (1973) recorded instances of the same phenomenon in the small workplace groups they respectively studied. The situations they described are usually oppositional and require special social negotiation strategies by the participants. For instance, the gossiper may need to avoid eye contact or otherwise simulate the nonpresence of the target. The clinicians Medini and Rosenberg (1976) believed that when clients or psychotherapists disclose relevant truths about themselves, it may be called gossip: gossip about the self. For these authors, the defining feature of gossip was that it contrasts the discrepancy between the public and the private life (cf. Goffman, 1959). It is the instrument "for those who wish to know how life is lived behind the social mask" (Medini \& Rosenberg, 1976, p. 462). Other instances in which the targets are present include certain culturally sanctioned public events. Gilmore (1978) reported on the Carnaval (or "fiesta of gossip") in a small Spanish community, where people take to the streets in a giant masquerade and hurl "slander, vilification, and innuendo" openly at each other (p. 93). Hollywood and private dinner club "roasts," good-natured ribbings honoring people of notable achievement, seem to perform essentially the same function: a public gossiping, but one made safe because of the ritualized nature and the obvious contrast with the re- 
doubtable achievements of the target. Ritualized gossip seems to come to the aid of practically all societies when the need arises to blow off some collective steam (cf. Stirling, 1956).

Nevertheless, circumstances that break the rule of an absent gossip target are relatively unusual and occupy a unique position in the social matrix. It may be that gossip about the self would better be labeled self-disclosure (Kuttler, Parker, \& La Greca, 2002), and when consequently passed to a third party, it becomes gossip. Gossip about others who are present is probably better labeled public disclosure or ridicule (Kuttler et al., 2002; which may or may not be made innocuous by other facets of the situation). For the most part, authors agree that day-to-day gossip refers to talk about absent third parties.

\section{Evaluative Content}

When we consider the valence of gossipy remarks - that is, positive or negative evaluations being made by the gossiper - considerable complexity and variation are introduced into the construct. Social conversation without valence is essentially the dissemination of human news: who landed a job or got admitted to college, who is having a baby, what products or services so-and-so uses, who moved in down the street, and the like. Assuming that, alongside these apparently bald facts, there are no implied notions that carry significant evaluative connotations, these items may be considered gossip of a benign and nonevaluative nature for general informational purposes. Tannen (1990) defined gossip in this broad way, requiring only the repetition of news about a third party, the passing along of everyday details. Bergmann (1993) relied on this same general definition of gossip, the passing of news about the personal affairs of others. Besnier (1989) and Hannerz (1967) appeared likewise content with a gossip lacking an evaluative component.

Nevertheless, for fruitful research purposes, limiting the definition of gossip to mere news dissemination is unsatisfactory for two reasons. First, popular understanding of gossip clearly includes a negative evaluative component that, in part, forms the basis for the social sanctions against its practice. Second, most exchanges of personal news carry with them some evaluative meaning implicit in the shared tacit knowledge, histories, and cultural norms of the conversationalists. Consequently, some theoretical social functions of gossip (described in more detail shortly) are such that they would be effectively eviscerated if the evaluative component were not an ingredient of the genre.

Thus, positive and negative evaluations (or tone) directed at a third party contribute to the social and research characterization of gossip. Such judgments carried along on the gossip channel have, indeed, great implications for how we choose to exist in concert with our fellow humans. Although the surface of a gossipy conversation may appear casual, idle, or trivial (Rosnow, 2001), the meta-communicative value is of quite a different kind when we include the evaluative components, implied or explicit, that usually accompany such communications.

When we consider the social and psychological functions of gossip, it is sensible to include positive evaluations in the definition of gossip, although the everyday idea of gossip rarely does. Sabini and Silver (1978); Rosnow (2001); Baumeister, Zhang, and Vohs (2004; this issue); and others adamantly include positive remarks under the general rubric of gossip. Mettetal (1982) observed positive and negative gossip among adolescents, although exchanges among younger peers were likely to be more negative, suggesting that maturity may play a part in developing a more subtle and complex form (Gottman \& Mettetal, 1986). Leaper and Holliday (1995) coded for both kinds of gossip in their recorded conversations and found gender differences along these lines. Noon and Delbridge (1993) acknowledged the possible positive consequences of gossiping behavior and limited their definition to "value-laden information" (p. 25), citing a distinction made by Elias and Scotson (1965) between "praise gossip" and "blame gossip." Dunbar (1993b) asserted that people should not hold gossip only to its pejorative sense (and doing so "says more about what these individuals talk about than anything else" [p. 729]). As noted earlier, Dunbar and his associates (1997) reported data showing that malicious gossip takes up only a smallthough, no doubt, important-part of conversational time.

Conceiving of gossip as having either positive or negative valence is hardly a novel idea: Machiavelli (1516/1995) maintained that "all 
men, when they are talked about, ... are remarked upon for various qualities which bring them either praise or blame" (p. 89). Gossip certainly influences reputations; yet, there is no logical reason to suppose that this is solely accomplished with negative remarks. Consolidation of power in the workplace, for instance, would require not only the denigration of rivals' programs but the extolling of preferred players' programs. Third-party information of both the positive and negative kind has been shown to augment people's opinions of their coworkers in either respective direction (Burt \& Knez, 1995).

\section{Situational Factors}

Content is not the only thing that distinguishes the gossip genre. Situation plays an important role, too. The Oxford English Dictionary includes little about the evaluative components of gossip just discussed and only glances at the situational aspects: As a noun, gossip is (1) in relation to the person baptized, a godfather or godmother, a sponsor; (2a) a familiar acquaintance, friend, chum, formerly applied to both sexes, now only (somewhat archaic) to women; (2b) applied to a woman's female friends invited to be present at a birth; (3) a person, mostly a woman, of light and trifling character, especially one who delights in idle talk, a newsmonger, a tattler; (4) the conversation of such a person, idle talk, trifling or groundless rumor, tittle-tattle; or (5) easy, unrestrained talk or writing, especially about persons or social incidents. But Hannerz (1967) and Rosnow (2001) have observed that context is a necessary consideration in establishing that gossip is present. Abrahams (1970) referred to the need for "the right setting and ... the properly licensed conditions" (p. 292) for gossip to occur; Yerkovich (1977) cited as a condition for gossip the congeniality of the situation; and Spacks (1982) asserted that "it's a certain atmosphere, most of all, that makes gossip recognizable: of intimacy, of gusto, often of surprise and revelation" (p. 30). The situational aspect of gossip cannot be entirely separated from the content of the gossip, any more than the functions of gossip can be separated from the form; the inherent meaning of the content depends on these other factors.
There are still other ways of defining gossip as it plays out in the human drama. Gilmore (1978) listed 11 different words used in a small Spanish community for varieties of gossiping behavior. Relevant variables he identified were purpose, agent, information value, intensity, status of target, and context. On some occasions in that society, the target of the gossip was intended by the gossiper to catch wind of it. Cross-status gossip had its own definition, as did gossip lacking deliberate instrumentality (regardless of the sensitivity of the target to the content). Some gossip would be discounted depending on the source and presumed to be exaggerated or untrue; this gossip, too, had a specific name. Gilmore extracted a four-part typology from these varieties of gossip, depending on number of gossipers, status of gossipee, instrumentality, and legitimacy (or credibility).

These examples serve to show that settling upon a final characterization of gossip for research purposes is not a simple matter. Yet, consistent with many researchers' observations, the most frequently encountered definition may be summarized as follows: In a context of congeniality, gossip is the exchange of personal information (positive or negative) in an evaluative way (positive or negative) about absent third parties. Definitions of the phenomenon may be more or less restrictive than this summary, as seen by the many typifications cited in this review (and this special issue), which demonstrate that one must be clear about the construct before embarking on data collection.

\section{Social Functions of Gossip}

It is not surprising that the social functions of gossip vary considerably from person to person, situation to situation, and (from the evidence offered in this issue) author to author. It may be said, however, that the literature has coalesced around four major social functions of gossip rooted in social exchange theories (viz., Blau, 1964; Foa, 1971; Homans, 1950; Moreno, 1993; Parsons, 1960). These functions were essentially foreshadowed in an article written by Stirling in 1956. She remarked upon gossip as socially beneficial in that it facilitates information flow, provides recreation, and strengthens control sanctions, thereby creating group solidarity. Yet, it also can be "an outlet for hostile aggression" (Stirling, 1956, p. 263). Stirling 
thus implied the four social functions of gossip encountered repeatedly in gossip literature in the years since her article: information, entertainment, friendship (or intimacy), and influence.

\section{Information}

As a mechanism of information exchange, gossip is frequently described as an efficient and, at times, exclusive means of gathering or disseminating information. From gossip, "the individual gets a map of his social environment" (Hannerz, 1967, p. 57), particularly in low-accessibility networks spread thin by high mobility. At the group level, gossip has been aptly called "a slow scanning of the total informational resource of the group" (Roberts, 1964, p. 441 ) or "a sort of tally sheet for public opinion" (Szwed, 1966, p. 435). The "official line," in this age of sophisticated and instantaneously informed publics, is often dismissed in favor of "the inside scoop" that only gossip can provide (Ayim, 1994; Crampton, Hodge, \& Mishra, 1998; Levin \& Arluke, 1987; Rosnow, 2001). Suls (1977) observed that, although it may be possible to communicate directly with other people regarding needed social comparison information, gossip may be the better means to such knowledge if the information sought is of an unfavorable kind. From the tradition of social exchange in psychology, gossip is often portrayed as a kind of currency, traded like any other, and assessed for its value by the taker on the basis of timeliness, usefulness, and, especially, rarity. Rosnow and Fine (1976) observed that the transactional nature of gossip seemed to parallel traditional patterns of economic exchange.

Bergmann (1993), in a related vein, believed that it is the unequal distribution of knowledge that makes the information spread through gossip valuable. The gossip producer's "reputation and position within the gossip triad is [sic] essentially determined by the potential and factual access he has" to information about others' private lives (p. 67). Baumeister et al. (2004), in this issue, agree that social status may be elevated by gossiping: Frequently, listeners infer that the gossiper is in possession of special knowledge or understanding of social rules and standards. For Rosnow and Fine (1976), the ideal exemplar of this stereotype is the profes- sional gossip columnist, a tradition, incidentally, that in the United States goes back to 1730, when Benjamin Franklin wrote a column for the Pennsylvania Gazette. Before then, in England, Addison and Steele's Tatler and Spectator, which were penny periodicals for the burgeoning middle class, were early prototypes of today's gossip columns. People looked to these gossipy writers, as people do today, as sources of social knowledge and the proper ways to live and behave.

The fact that informality and privacy are important conditions for the transmission of gossip (Hannerz, 1967; Schoeman, 1994) necessarily makes gossip "scarce," because people naturally guard the flow of information about themselves (Derlega \& Chaikin, 1977; Hannerz, 1967; Haviland, 1977; Szwed, 1966). Yerkovich (1977) pointed out that "information, no matter how salient or scandalous, isn't gossip unless the participants know enough about the people involved to experience the thrill of revelation" (p. 196). Bergmann (1993) wrote that informational exchanges between spouses at the end of the day might not be gossip for that very reason: "The 'thrill' and commitment does [sic] not nearly reach the normal dimensions of gossip conversations" (p. 68), although precisely where along this continuum gossip begins or ends is certainly hard to say.

People sometimes go to extraordinary lengths to gather personal information about their fellow humans. Haviland (1977) reported people habitually peeking in their neighbors' doorways, and children have sometimes been recruited as proxies (Goffman, 1959; Haviland, 1977; Hotchkiss, 1962). The latter, Rosnow (2001) pointed out, has the double advantage of easy access and impunity from sanctions for later spreading the information. Priests and politicians have resorted to making liquor available to facilitate information flow between the classes (Szwed, 1966). Social workers in remote areas have recognized that the pains of extreme isolation can be ameliorated by passing some "constructive gossip" to their clients, because "gossip at its worst is far better than no attention at all" for these socially isolated people (G. W. Brown, 1985, p. 387). In the same vein, Medini and Rosenberg (1976) believed that the informational value in passing gossip can be restorative and therapeutic by way of "the same boat phenomenon" (p. 454)—not an especially so- 
phisticated therapy approach, perhaps, but presumably useful.

\section{Entertainment}

Gossip as entertainment can be readily inferred by observing conversationalists passing the time gossiping. Although the gossipee might certainly be sensitive about the information being passed, this does not obviate the fact that gossip can exist solely for the entertainment or recreational value of the gossipers. It is "the sheer fun which for most gossipers explains their involvement" (Spacks, 1982, p. 31). BenZe'ev (1994) and Stirling (1956) remarked on the obvious pleasure derived from gossiping, as did Rosnow (1977), who maintained that there are times when gossip serves no external purpose of exploitation or influence but merely the immediacy of amusement. Gelles (1989) observed that gossip, in its use of storytelling, satisfies the emotions in the same way that literature can; Spacks (1982) concurred. In the Spanish rural community he studied, Gilmore (1978) explained that gossip provided the primary source of entertainment: "Nothing is enjoyed so thoroughly or treasured so preciously" (p. 92). In certain work environments, gossiping can provide relief from monotony, as Roy (1958) experienced in his 2-month stint as a factory worker. And although the mass media production of gossip concerning public figures such as actors, politicians, and sports figures is constructively different in a number of ways from privately conducted gossiping about targets the participants know directly, the entertainment value of gossip is clearly the basis of this enormous cultural and economic enterprise.

To some degree, it may be said that the entertainment value of gossip occurs outside the actual exchange. As with buying a lottery ticket or waiting for the next at bat while watching a baseball game, there is enjoyment in the intervening moments, a carryover of interest as to what change and new elements future tidbits of information or action might bear. In any event, gossip-before, during, or after the exchange-is a bulwark against life's monotony, providing considerable stimulation for very little cost. Perhaps, as Spacks (1982) maintained, we cannot fully account for the entertainment value of gossip: To explain what is rewarding in gossip is "like efforts to elucidate what's funny in a joke" (p. 21).

\section{Friendship}

The friendship or intimacy function of gossiping refers both to dyadic interchanges and to the way in which gossip brings groups together through the sharing of norms, thereby establishing boundaries to distinguish insiders from outsiders. What begins as a trusted exchange in private becomes at the group level the knowledge, norm, and trust boundaries of tribes, clans, and cultures.

Sharing gossip is a way to telegraph to the listener the gossiper's confidence in the recipient (Hannerz, 1967). If the gossiper is relatively sure of the security of the "dyadic boundary," he or she will feel safe in disclosing to the listener (Derlega \& Chaikin, 1977) and so cement the relationship. The relationship between Monica Lewinsky and Linda Tripp during the William J. Clinton presidency was an example in high Washingtonian circles of this expectation, although, of course, it was breached in historic fashion.

In other contexts, a number of authors have observed the likelihood of gossiping with and, to a lesser extent, about friends (Blumberg, 1972). "People in this town can't keep their mouths shut, and the worst of all are your friends," complains a villager (Gilmore, 1978, p. 94). Notwithstanding the "strangers on a train" phenomenon (Bergmann, 1993; Derlega \& Chaikin, 1977), gossip is less likely to take place between casual acquaintances or strangers than between friends (Blumberg, 1972), probably because shared social meanings and history are essential to understanding the subtleties of the gossip (Abrahams, 1970; Noon \& Delbridge, 1993).

At the group level, Gluckman (1963) noted how outsiders simply cannot understand gossip, and at times it is deliberately used by insiders to exclude outsiders (Dunbar, 2004; Eckert, 1990; Loudon, 1961; Noon \& Delbridge, 1993). Newcomers find themselves struggling to stay up to speed in casual conversations, wherein meanings are firmly rooted in long and complicated histories and, in the case of professional groups, frequently expressed in arcane jargon (Gluckman, 1963). Yerkovich (1977) tracked how evaluations of discrete events gradually became 
categorized abstractions comprising "the store of shared knowledge that familiar individuals use when they interact with one another" ( $p$. 194). Outsiders risk infringing on group values if they do not wait for the group to induct them (Abrahams, 1970) in a process that sometimes develops into a ritual or rule-bound ceremony (Noon \& Delbridge, 1993; Roy, 1958) not officially sanctioned and formalized but nonetheless tacitly necessary to joining.

\section{Influence}

Establishing friendship at the dyadic or group level is closely related to boundary enforcement and gossip's influence function, widely discussed by gossip writers. As a means of corralling (or expelling) the wayward and eccentric, gossip is acknowledged to be an efficient social mechanism. The aim of gossip could be either to reform or to stigmatize the sinner, as Cox (1970) put it. Enquist and Leimar (1993) and Dunbar (2004), in this volume, maintain that gossip is a kind of informal policing device for controlling free riders and social cheats. In fact, these authors posit that, evolutionarily, this is the most important function of language in general and gossip in particular.

It is not much of a deductive leap to realize that what one hears about others can just as easily be said to others about oneself; in this way, we can learn how to behave-what to do and what not to do-from listening to gossip. Children no doubt learn the norms of their culture, neighborhood, and various professions by listening to frequent object lessons concocted ad hoc by parents. Coworkers learn what is expected of them by hearing stories holding high performers up to praise and low performers to shame; the "corporate culture" in an organization is commonly expressed this way in gossipy stories (Kurland \& Pelled, 2000; Noon \& Delbridge, 1993). Indeed, culture in general depends on repetition of norms and mores in many forms, both formal and informal, to maintain its hold on members. Gossip is arguably the most common form because it requires no special skill to produce, as do storytelling and singing, for instance (Abrahams, 1970). Many forms of social comparison-and, therefore, social understanding - may be expressed in the form of gossip (Wert \& Salovey, 2004). Baumeister et al. (2004), in this issue, present evidence that a primary function of gossip is cultural learning in a general form.

Much of Gluckman's (1963) research focused on the coercive aspect of gossip from the perspective of the group. Paine (1967) countered that it is "the individual who should be taken into account in forwarding and protecting individual interests" (p. 278). Building on the work of both Paine $(1967,1970)$ and Goffman (1959), Cox (1970) wrote that gossip occurs when a person "directly interferes in another's impression-management, hence forcing the audience to redefine his victim's role" (p. 88).

One of the conditions for gossip to be influential is that people must agree on the norms for behavior and what constitutes acceptability; gossipers typically articulate these things. Eckert (1990), for instance, in her study of adolescent girls' gossip, referred to a "good person" (p. 95) as having acquired symbolic capital in the eyes of his or her age group and, therefore, having relatively more power to influence others. Such people are repositories of group norms, and their opinions therefore have more weight in shepherding conformity. Conformity is essential for the survival of the group as a whole, which may account for the particularly vitriolic form of gossip observed in groups under pressure to survive and in open competition with one another (Cox, 1970; Gluckman, 1963).

Gossip's potential to restrict freedom motivates people not only to minimize their eccentricities but also to minimize gossip about themselves whenever possible. People might try to be present, for example, when they sense they may be being talked about (Gilmore, 1978), or they may try to ferret out the sources of gossip about themselves. Haviland (1977) observed that although people are intensely and often indiscreetly curious about their neighbors, they go to considerable lengths to hide details of their own daily lives. Szwed's (1966) Newfoundlanders also guarded themselves by various means against "overexposure." Residents in Gilmore's (1978) Spanish town did not even invite neighbors into their homes, for fear of giving them the opportunity to talk about "all that is "wrong'" (p. 94) there. Although vulnerability to the influence of gossip will vary from person to person, most of us choose to protect our membership in our respective groups by conforming at least outwardly to 
many norms, the breach of which is likely to be circulated in the form of gossip.

The influence function of gossip probably contributes significantly to the popular kneejerk denigration of the practice. However, as this catalog has shown, gossip can also provide an uncomplicated, benign pastime for many; hold communities together against the forces of social entropy; cement dyads and groups with trust and intimacy through private disclosures and reiteration of norms; and relieve profound isolation for some in remote locations or through therapy. Just as gossip divides, it may also bring together and provide harbor; its boundary-making property both includes on the one hand and excludes on the other. For these reasons, gossip should be understood to include negative and positive valences, in both content and effect, if the social functions of gossip regularly discussed are to make the fullest nomothetical sense.

\section{Other Functions of Gossip}

\section{Evolutionary Utility}

The field of evolutionary biology provides a unique perspective on the social functions of gossip, predictably reducing them to one critical function: survival. Barkow (1992) suggested that gossip was selected for among our ancestors because it provided information necessary for survival. News and evaluations about "relatives, rivals, mates and potential mates, offspring, partners in social exchange, and the very high-ranking" would be of particular interest, as would "control over resources, sexual activities, births and deaths, current alliances/friendships and political involvements, health, and reputation about reliability as a partner in social exchange" (Barkow, 1992, p. 628). With such a large part of everyday life taken up with social information exchanges, it was inevitable that the search by theorists and researchers for an adaptive, evolutionary mechanism for gossip would arise.

Dunbar (1992, 1993a, 1993b, 1994) has presented a cogent argument for the development of gossip (and human language in general) based on data about primate grooming behaviors, socially coherent group size, and neocortex/rest-of-brain volume ratios. The thrust of his proposition is that, as primate groups become larger, they need a more efficient way to maintain social coherence than that afforded by grooming. (Nonhuman primates have complex social structures demonstrably based on dyadic grooming relationships.) By what means did human animals maintain the social coherence of groups much larger than nonhuman primate groups without encroaching on essential foraging time? Language is Dunbar's answer, because it affords efficient exchange of social information.

Language thus becomes "grooming at a distance." "In effect, humans were now exploiting the greater efficiency of language as a bonding mechanism to allow themselves to live in larger groups for the same investment of social time" (Dunbar, 1994, pp. 115-116). Language not only allows members of the group to interact with a wider set of individuals at any one time by exchanging socially relevant information, it also greatly speeds up the process of acquiring the information (Dunbar, 1993b). To keep track of the social world, the social animal "needs to know who is in and who is out, who is friends with whom, and who is the best ally of the day. ... The animal has to keep track of all this, constantly updating its social map with each day's new observations" (Dunbar, 1994, p. 66). As groups increase in size, the number of thirdparty social relationships needing to be kept track of increases exponentially. This, concluded Dunbar, is the mechanism for the evolution of gossip. Gossip-and the computing hardware required to process it-evolved to solve the major adaptive problem of larger group sizes.

\section{Dynamic Utility and Guilt}

A number of writers have used the phrase "letting off steam" as a purpose of gossip (Gilmore, 1978; Levin \& Arluke, 1985, 1987; Rosenbaum \& Subrin, 1963; Stirling, 1956). This function implies a cathartic release from anger, guilt, anxiety, or some other unpleasant internal state and a return to a balanced state of repose. Inevitably, any such mechanism in the extreme can go awry. In a case related by Rosenbaum and Subrin (1963), a man is socially debilitated owing to his compulsive habit of passing obviously made-up gossip and his deliberate attempts to stir up mayhem by setting people against each other. Another case in- 
volves a woman who gossips incessantly to friends about others who are ill in hospitals. Perhaps gossiping has psychological utility for dealing with hostility and fear. In Freudian terms, in such cases, it may be a discharge of Oedipal longing, the cathecting of latent fantasies, or trace expressions of sibling rivalry that motivates gossip in a bid to curry authority's favor (Rosenbaum \& Subrin, 1963). Some social insights can be found in the dynamic view that gossip is a means of displacing inherently irresolvable hostilities. Substitution of the object of fear, hostility, or envy with a gossip target can sometimes result in social bonding and group formation. Gossip about newly hired employees in the workplace, for instance, probably as common as gossip about authority figures, serves to relieve an intractable unease from unknown forces at the same time it validates the status quo.

The observation of gossip alloyed in some manner with guilt is a frequent one. Eckert (1990) noticed the dilemma adolescent girls face if they are to uphold norms by gossiping about those who break them: The upholders must themselves break a norm by gossiping. Awareness of the cost to others (even if they remain unaware of it) ineluctably accompanies the gossiper. Spacks (1982), generally an apologist for gossip, recognized its harmful potential as an "indigestible problem" (p. 29) and acknowledged the irreducible complexity of the phenomenon: "Few gossip without guilt, few defend without ambivalence" (p. 21). It seems at times that gossip generates as much guilt as its production simultaneously relieves.

Bergmann (1993) referred to the pervasive ways in which people assuage their guilt as "neutralizing behaviors" (p. 77) designed to divert attention from the compromising ethics of spreading or even hearing news about absent others. One reason the workplace is often a hotbed of gossip, he asserted, is that legitimate work activities provide a convenient cover "so that [gossip] appears as the unintended, accidental, and thereby excusable activity of an occasional gossiper" (Bergmann, 1993, pp. 7778). Thus, people camouflage their motives by "accidentally" and passively acquiring private information. Though gossip may not be the central purpose, but rather a byproduct of the larger situation, it is only apparently superfluous (Rosnow, 2001), as we pretend to be absorbed in "serious" thought or activity while attending closely to gossip around us. This is both the external embodiment and denial of guilt.

The desire to defend against the guilt accompanying gossip is pervasive but sometimes more subtle than retreating to covert discussion. A number of writers have noted a conversational tick of some kind that loosens the mantle of guilt and deflects culpability for the gossiper. Haviland (1977), for instance, noted that ". . . or so I hear" tacked onto a gossipy remark could protect the gossiper from harsh judgments. Bernstein (1984) observed the phrase "it's just talk" as serving a similar purpose. Another manifestation of this reluctance to face the nature of gossip squarely is the plethora of euphemisms employed to name it: shooting the breeze, shop talk, chit-chat, kibitzing, chewing the fat, emotional speculation, being in the loop, hock a tchainik, "nothing really" (in answer to "what did you talk about?"), the scoop, the inside story, small talk, soap, dope, killing time together, socializing. In addition, complete linguistic substitutions are frequently made for what are essentially gossipy gatherings: "let's go for coffee," "let's have lunch sometime soon," "a cocktail after work," "bridge on Fridays," "meet me for a drink?" The list of such pretexts is, of course, endless. The evasiveness of these locutions is evidence that gossiping is not universally approved of, and their sheer number brings us back to the paradox noted at the opening of this article: Predictable and persistent disapproval has made nary a dent in the ubiquity of the practice.

Seen through the lenses of social function, survival, dynamic utility, and guilt, a motivational view of gossip emerges. That gossip blossoms in the presence of many messages and cues to curtail it supports the view that there may be strong motivations to gossip. It is generated to resolve numerous internal tensions (Wert \& Salovey, 2004) or achieve external goals. As with many behaviors and emotions, however, people are not necessarily phenomenologically aware of their gossiping motivations. Baumeister et al. (2004), in this issue, make the analogy that, just as sexual desire may be independent of reproduction, gossip may contribute to cultural learning even if people are not aware of their desire to promote such learning by gossiping. More than once in my own experience, a research participant has spontane- 
ously denied ever having gossiped, yet in the next sentence conveyed something patently gossipy. Identifying the motives behind and conditions moderating such behavior warrants a solid place for gossip research in the general psychological literature, ripe for new methods of investigation.

\section{Methodologies Used in Gossip Research}

Gossip research has roots in many disciplines, which contributes to a wide variety of research methods. This section categorizes some of these approaches, not as an exhaustive review but, rather, as a brief description of the most common methods and their benefits and drawbacks.

\section{Participant Observers}

Important early contributions to gossip theory came from social anthropology and its subspecialty, ethnography. Numerous investigations consisted of traditional field studies, with the researchers more or less immersing themselves in the culture and recording events as they happened. Participant-observer field studies require a large time commitment, but they return a rich store of primary data, typically in the form of field notes jotted down in close temporal and physical proximity to actual events. Table 2 lists most of the major participant-observer studies in gossip research, along with the time commitments involved (as disclosed in the articles).

Table 2

Participant-Observer Gossip Studies: Time to Completion, Location, and Notes

\begin{tabular}{|c|c|c|c|}
\hline Study & Time to completion & Location & Notes \\
\hline Besnier (1989) & $\begin{array}{l}\text { Time during 1980-1982 and } \\
\text { in } 1985\end{array}$ & Pacific isle & $\begin{array}{l}\text { Recorded } 10 \mathrm{hr} \text { of gossip in } 15 \\
\text { settings, capturing } 8.6 \% \text { of } \\
\text { the inhabitants }\end{array}$ \\
\hline Eder \& Enke (1991) & $\begin{array}{l}\text { "On a regular basis for three } \\
\text { years" (pp. 495-496) }\end{array}$ & $\begin{array}{l}\text { Middle school in a medium- } \\
\text { sized midwestern } \\
\text { community }\end{array}$ & $\begin{array}{l}\text { Audiotaped or videotaped } 4 \text { to } 8 \\
\text { conversations of } 11 \text { different } \\
\text { groups each, } 79 \text { students } \\
\text { total; ethnographic notes also } \\
\text { used "to help interpret and } \\
\text { analyze recorded data" (p. } \\
\text { 496) }\end{array}$ \\
\hline Gilmore (1978) & $\begin{array}{l}\text { Time during } 1972-1973 \text { and } \\
\text { a month in } 1977\end{array}$ & Rural Spanish community & $\begin{array}{l}\text { Used "the standard observation- } \\
\text { participation methods" (p. 99) }\end{array}$ \\
\hline Handelman (1973) & $\begin{array}{l}\text { Not specified, recorded } \\
\text { many conversations of } 16 \\
\text { full-time workers }\end{array}$ & Israel & \\
\hline Hannerz (1967) & $\begin{array}{l}\text { Not specified, but long } \\
\text { enough to "get } \\
\text { established in personal } \\
\text { relationships with [the } \\
\text { neighborhood] inhabitants } \\
\text { by way of frequent, } \\
\text { seemingly casual } \\
\text { encounters" (p. 45) }\end{array}$ & $\begin{array}{l}\text { An "American ghetto" in } \\
\text { Washington, DC }\end{array}$ & \\
\hline Haviland (1977) & $\begin{array}{l}\text { "From time to time over the } \\
\text { past ten years" (p. 186) }\end{array}$ & Zinacatan, Mexico & $\begin{array}{l}\text { Author and his family set up a } \\
\text { household and lived there }\end{array}$ \\
\hline Loudon (1961) & Between 1957 and 1960 & Wales & \\
\hline Roy (1958) & $\begin{array}{l}\text { Two months, full-time } \\
\text { factory work }\end{array}$ & $\begin{array}{l}\text { Factory, location not } \\
\text { specified }\end{array}$ & $\begin{array}{l}\text { Became coworker of his } \\
\text { participants }\end{array}$ \\
\hline Szwed (1966) & Time during 1962-1964 & Small town in Newfoundland & \\
\hline Yerkovich (1977) & One year & $\begin{array}{l}\text { "Sharing the life of an upper } \\
\text { middle-class white Anglo- } \\
\text { Saxon urban community" } \\
\text { (p. 192) }\end{array}$ & $\begin{array}{c}\text { The approach was "influenced } \\
\text { by. . the ethnography of } \\
\text { speaking" (p. 192) }\end{array}$ \\
\hline
\end{tabular}


There are a number of benefits to this kind of research. Close observation of communications as they unfold is an unparalleled way to gather social data. Ideally, patient adaptation to the surroundings on the part of the researcher eventually makes his or her presence relatively unobtrusive, and genuine behavior or details that are often captured poorly after the fact by selfreport can be observed with immediacy and sensory continuity. Much situational information, including status relationships, personal and interpersonal histories, and the routine daily activities of those observed, may also take on importance and lend evaluative meaning to the interpretation of gossipy exchanges. Roy (1958), for instance, realized that it took some time after beginning a factory job before "the disconnected became connected, the nonsense made sense, the obscure became clear, and the silly actually funny ... the interaction began to reveal structure" (p. 161). Had he not taken the time to acquire such knowledge, the subtleties of the repartee among his coworkers would have remained obscure and subject to significant misinterpretation.

Attempts by researchers to overcome boundaries are not always successful, however. Gluckman (1963), cited heavily in gossip literature, noted how he could not penetrate certain groups "because I did not know enough gossip.... The outsider cannot always detect the slight personal knockdown" (p. 309). Gluckman spent a significant portion of his classic 1963 article discussing the work and observations of Elizabeth Colson, who spent many hours interviewing the Makah Indians of the Northwest. She came to see that Makah gossip is far more than in-group aggression; it is a means of reasserting central values of the culture. However, like Gluckman, she sensed her own position as an outsider among them: "Only others of their own community have the technical knowledge to compete in the game, or to appreciate the skill with which a point is scored" (Colson, 1953, p. 228). Such limits of field study were brought front and center by P. Wilson (1974), who questioned the presumptions and conclusions of Colson, citing other evidence that the Makah probably mistrusted her and misled her with their self-reports. Thus, to be just an observer and not a participant means risking "not getting it."
Nevertheless, a good deal of our current theoretical knowledge about gossip comes from field studies such as the ones just described. Hannerz (1967) remarked that "probably there is no other way of acquiring knowledge about gossip" (p. 45). This is an overstatement perhaps, but it reflects the value of the method, to be sure.

\section{Video and Audio Recording}

Other researchers, because of demographic distance from their subjects, do not become "participants" but still collect information directly, usually by ingratiating themselves with their subjects and then recording conversations. Eder and Enke (1991), for instance, studied adolescent boys and girls (10 to 14 years of age) in a middle school setting. Over a period of 3 years, these researchers ate lunch with students in the cafeteria or attended other activities. In time, the observers felt they had achieved a high level of rapport. They then recorded 16 gossiping episodes and, by scrutinizing transcripts, found that gossipers' remarks tend to be sensitive to what immediately precedes as well as to what is expected to follow, because the discussants are aware of a predetermined, surprisingly predictable (although certainly complex and flexible) conversation structure. In particular, the first response to an opening remark about a gossip target would decisively determine the direction the remainder of the episode would take: "Responses to [target] evaluations are more important than the evaluations themselves in determining the nature of subsequent responses" (Eder \& Enke, 1991, p. 505). In addition, expressions of agreement with remarks about an unknown target (and later support for the view the group expressed as a whole) demonstrate the group-norm-maintaining function of gossip in action.

Mettetal (1982) transcribed audiotapes and videotapes of girls 6-17 years of age and coded the frequency and valence of gossiping behavior, finding that within this particular group, talk about third parties was negative about half of the time and that, unlike some instances with Eder and Enke's subjects, the targets were always known to both parties doing the gossiping. Planalp (1993), in her judges' analyses of recorded conversations, also found that mutual knowledge of third parties was a discriminant 
factor in predicting whether interactants were friends or acquaintances. Nicolopoulou (1997) traced how the thematic content of boys' and girls' gossip and conversations became more differentiated over the course of a school year. Besnier (1989) recorded and transcribed some 50,000 words of conversation among inhabitants of a small Pacific island, yielding finegrained data on gossip productions and how gossipers co-create their gossip. In particular, he showed how leaders in the conversation manipulated their listeners to contribute gossip. Many authors, in fact, have remarked on this collaborative facet of gossiping exchanges. Baumeister et al. (2004), in this issue, also point out that, cognitively, collaboration in the development of a gossipy conversation necessarily augments the social learning value of the exchange because the content is better remembered and more likely to be repeated.

\section{Eavesdropping}

The solution of a number of researchers to the problems of exclusion or altering the social relations of those observed has been to eavesdrop in public places. This approach preserves the interactional aspects and spontaneity of gossiping. By spending hours in a campus meeting place, for instance, Levin and Arluke (1985) cataloged features of gossip they overheard, which presumably was unaffected by their presence. The authors found virtually no differences in degree of gossip between men and women but some differences in content (women talked more about relationships; men talked more about sports figures and other public figures). Dunbar et al. (1997) also eavesdropped in public places, and McCormick and McCormick (1992) lurked online to find a high concentration (52\%) of "social topics" in an analysis of e-mail messages.

Although unobtrusive, there are a number of inherent disadvantages to the eavesdropping method. People may be responsible for what they say in a public place, but we must ask whether they have a reasonable expectation of privacy. Should they know when they are being research participants, even if the method used is completely noninteractive and anonymous? Thus, ethical issues arise. Further, the researchers have no way of collecting information about the gossipers, such as the length of time the parties have known one another, the status relationships involved, or any other relevant history. Information on the targets and their relationship to the gossipers, too, is necessarily sketchy at best. The fact that these conversations occurred publicly may have put some constraints on the types of information transferred (although, to be sure, most of us have had some experience with overhearing astonishingly indiscreet exchanges in public). Selection bias must be taken into account as well, because these are typically convenience samples.

\section{Questionnaire Studies}

Participant observation, recordings, and eavesdropping all provide descriptive data on the phenomenon of gossip and can capture some of the richness and complexity of the behavior as it occurs. There are fewer correlational studies involving the use of questionnaires. One such study was conducted by Jaeger, Skleder, Rind, and Rosnow (1994) with sorority members as participants. Acknowledging the difficulty of gathering empirical information on what is essentially a secretive or, at least, private behavior, these researchers gathered psychometric and network data on members of a sorority in an effort to capture personality information about both the gossipers and the targets of gossip. The authors were not present at actual gossiping events or privy to the histories of the sisters; however, the data nevertheless shed quantitative light on a number of gossiprelated issues. On the basis of self-reports made over several weeks, correlations were calculated on the participants' degree of gossiping behavior (or tendency to be a target of gossip) and other factors such as need for approval, selfesteem, general anxiety, and a rough measure of social network position. Among other results, the authors found that moderate gossipers tended toward the social middle (i.e., high and low gossipers have fewer close contacts). High gossipers tend to be more anxious, yet lower in need for social approval. And those less likely to be gossiped about are higher in need for social approval, yet have fewer friends; those more likely to be targets report more friends.

Nevo et al. (1993) conducted a quantitative study after developing their own "tendency to gossip questionnaire" (TGQ). They also administered a social desirability scale to correlate 
with their participants' tendency to gossip; as expected, the correlation was negative $(r=$ $-.33)$. Also reported from the TGQ was a tendency of women to gossip more than men $(r=$ .20). However, the authors conceded that "social pressure may lead men to under-report their tendency to gossip.... Men may engage in gossip almost to the same extent as women" (Nevo et al., 1993, p. 980). This study was perhaps the first in the gossip canon to use a specifically gossip-related instrument. The development and application of such instruments carry the caveats that typically accompany selfreport data: People may not be particularly attuned to the behavior being inquired about, or they may have conscious or unconscious motives for slanting reports about their own behaviors.

\section{Experimental Research}

Several innovative experimental studies have been done on gossip, all relying on hypothetical vignettes. D. S. Wilson, Wilczynski, Wells, and Weiser (2000) presented participants with systematically varied fictional gossip scenarios and obtained approval ratings of the targets, gossipers, and listeners in the scenarios. The results implied that gossip (or fictional gossip, at least) that serves group norms reflects better on the gossipers and more harshly on the targets than gossip that is self-serving. Also, interesting gender interactions were found. After exposure to types of gossip, such as true and false negative gossip, men and women responded about equally positively to truthful gossip, but women responded more negatively to false gossip. Men responded more positively to speaking directly to the supposed transgressor of a norm, and they responded much more negatively than women did to a do-nothing approach. Men and women equally disapproved of self-serving gossip. These results support a hypothesis that people generally approve of negative gossip in response to norm violations.

Kuttler et al. (2002) also used fictional scenarios to gauge sensitivity to variables that might influence the perceived veracity of gossip. They found that preadolescents have a surprisingly keen sense of the restraints they should impose on third-hand information. A large number of third through sixth graders were presented with vignettes involving differ- ing cues. Conflicting information from the targets themselves or from or between third parties contributed ambiguity to the gossipy communications in the stories. The reliability of speakers in the stories was manipulated as well, having them transmit untrue information either intentionally or unintentionally. Strong majorities of the participants did perceive the transmissions as being gossip, and this perception was strongly associated with labeling the behavior as unacceptable. Simple, unambiguous gossip, however, had the lowest effect in this regard, $\chi^{2}(1, N=384)=32.33, p<.001, r_{\text {effect size }}=$ .29 , and both intentionally and unintentionally false remarks had the highest, $\chi^{2}(1, N=$ $384)=72.41, p<.001, r_{\text {effect size }}=.43$ for both. In reporting their confidence with the information passed, the youngsters showed some sensitivity to the conflicting cues in the gossiping situations. For instance, the children were surer of information when facts conflicted from two third parties than when facts conflicted when heard from the actual source (target) and a third party, $t(382)=3.38, p<.001, r_{\text {effect }}$ size $=.17$. An interesting finding was that the younger children tended to be somewhat more skeptical of the gossip than the older children, $t(382)=3.30, p=.001, r_{\text {effect size }}=.17$.

Finally, Blumberg (1972), though never using the word gossip, designed two studies to explore the "communication of interpersonal evaluations." His experiments showed a strong likelihood that evaluations stop short of targets $(r=.76)$; there was some interaction, however, with more positive evaluations reaching their targets than negative ones $(r=.20)$. Positive evaluations were also more likely to be shared with either close friends or more distant acquaintances. Blumberg's first study involved hypothetical statements about passing evaluations. His second inquired about actual events and circumstances. Although still open to selfreporting limitations, the results were consistent with the first study. One drawback of the second study was that it involved only female participants.

\section{Future Directions}

On the basis of existing literature, it is safe to conclude that social perception is often affected by gossip, as humans spend a significant portion 
of their interactions participating in gossip in one form or another. I have reviewed the basic definitions of the construct and described the most common methods used in this area of research, most of which has been conducted in social sciences other than psychology. There remain numerous questions about the topic that need exploring to produce further insights into this ubiquitous social activity.

Methods more sophisticated than eavesdropping and more convenient than ethnography need to be developed and applied. Certainly, more experimental work with randomized assignments is warranted. As mentioned earlier, D. S. Wilson et al. (2000), Kuttler et al. (2002), and Blumberg (1972) systematically varied gossip scenarios and then asked for ratings of various kinds, with interesting results. S. Wert (personal communication, February 24, 2002), of the Psychology Department at Yale University, has reported that spontaneous gossip can be generated in a laboratory and affected by self-esteem manipulations. Independent variables such as stimulus, source, mood, social context, and group composition may be manipulated. Dependent variables of interest might be belief in the veracity of the gossip, likelihood of transmission across status boundaries, feelings while hearing or producing gossip, changes in attitudes toward sender or target, and other cognitive and affective elements.

Factors that determine people's response to gossip and how they act upon it could help explain how gossiping plays a role in social cognition and relationships. Do people's selfperceptions of gossip correspond to their assumptions about how others gossip, or is there a self-serving bias? How aware are individuals of the gossiping they do? Emler (1990), for instance, showed experimentally that people are likely to exert considerable effort to protect their reputations, particularly with those closest to them and more so in "dense" social networks (i.e., networks with a relatively high percentage of dyadic contacts). This suggests that people have a keen sensitivity to gossip and its effects. Two additional issues are relevant: Do those "in the loop" have a competitive advantage in the social, economic, or political marketplace? Do groups that gossip more on average than their rival groups also have a competitive advantage or disadvantage? Longitudinal studies could ex- plore whether amount of gossiping activity or skill contributes to social difficulties or adjustment, at both the individual and the group level.

Assuming that gossip was essential to our prehistoric ancestors' survival, as Dunbar and others maintain, certain physiological and neurological processes might be measurably affected at the moment of gossip production and perhaps even by overtures to gossip. In a series of impressive experiments involving brain imaging with magnetic resonance imaging (MRI) and functional MRI (fMRI), Damasio (2000, 2001) and Adolphs and Damasio (2000) showed that simply asking respondents to imagine certain emotional events in their lives produces activity in specific areas of the brain. Work of this kind could yield important data on how gossip information is stored and retrieved and how much of the brain is involved in processing it. Manipulating type of gossip, targets, or partners may activate different parts of the brain and neurohormonal systems. Analysis of fMRIs and other data could thus lead to neurobiologically based models of gossiping behavior designed to scrutinize and explain the nature of gossip as a social, biological, and even survival mechanism.

Another avenue of inquiry is whether, during gossip production, people believe it has, or intend it to have, consequences outside of the conversation. Degree of interest in heard gossip may depend on how engaged individuals are with the target and the source, as well as with the content. H. Hom (personal communication, February 25, 2002), of the Psychology Department at the University of Virginia, has developed a diary-type questionnaire to capture data aimed at answering questions along these and other lines.

Further survey research could produce muchneeded parametric data. The social functions of gossiping behavior, as noted earlier in this article, are frequently identified by observers. I have developed and used an instrument that differentiates these functions moderately well and reliably; it is appended to this article. A theoretical objective in organizational settings might involve determining how the social functions of gossip are affected by the nature of the formal network (the organizational chart or prescribed network). Does gossip become more "informational" or more "influential" in a strongly hierarchical organization? Relative to 
typical workplaces, groups without a nominal economic purpose (e.g., clubs, dormitories, congregations, and study groups) or groups with more or fewer status ranks may shift the motivational functions of gossip in predictable ways. Answers to such questions could aid in building models of the social and organizational processes of gossip.

On the assumption that the perceived environment guides behavior to some degree, I have also examined gossip with sociometric methods to determine how gossiping behavior and the structure of the social network interact. One question that may be answered with network data is whether those who gossip more than average in relation to their local peer group are more, or less, connected to the members of that group. That is, is there a linear relationship between one's connections to a network and how much one gossips? Or, as some have proposed, is there a quadratic relationship whereby, to maximize their knowledge of the network, people gossip neither too much nor too little, but "just the right amount"? In a study of 46 residence assistants (RAs) at a small college, I found evidence of a strong, positive linear relationship between the number of times one is named as a gossip partner by one's peers and the amount of social connection one has in addition to these partnerships $(r=.67$; Foster, 2003). It is possible that the complete lack of a quadratic relationship was due to a restriction of range, but of what dimension(s) remains to be determined.

The value of social network analysis in gossip research is also hinted at by a typology of gossip that emerged in the RA study. Through the use of a technique that distinguished social group members according to the similarity of their gossip connections to and from one another, four identifiable groups emerged from the highly complex gossiping interrelationships. First was a group whose tenure as RAs was longer than that of others. These folks were well established socially, as they had many gossip partners. However, they reported a lower frequency of contact and less RA-related advice seeking. The second group differed from the first in that they tended to be newcomers. They also had many gossip partners, but they had a high frequency of contact with others, sought much RA-related advice, and reported many close friendships among other RAs. (This group resembled the "freshman class" Wert and Salovey [2004] discuss elsewhere in this issue.) In other words, the second group was getting in touch with the network; the first group was staying in touch.

The third group, very unlike the first two, reported few gossip partners (and were named very infrequently by others as gossip partners, as well). They had a low frequency of contact with others, generally did not seek out advice from their RA peers, and did not report close friends among the RAs. They were social "black boxes." Finally, a fourth group established close friendships, but not much in the way of gossip partners, advice seeking, or frequent contact with others. These people were sociable enough, but they did not frequently employ gossip or advice seeking as part of their social repertoire.

Figure 2 summarizes these groups in a $2 \times 2$ typology, along with suggested dimensions on the axes that seem to differentiate the groups. Members of the two groups composing the upper half of the grid, relative to those in the lower half, manifested interest in the network beyond their immediate neighborhood, as indicated by relatively high numbers of gossip partners. Members in the left half of the grid appeared to be less active than those in the right half in their approach to social information exchanges in general, in that they had less frequent contact and fewer types of contact with other members of the network. Certainly, there were "bridges" across the boundaries of these four groups, but the in-group bias for gossiping within them was strong.

Additional network issues may be explored with social network analysis. Network density (i.e., "close knit" or "loose knit" on various kinds of links), for instance, may have measurable effects on both the frequency and type of gossipy communications. Further, network location information is easily captured in sociomatrices, presented in sociograms, and examined with network analysis. Network proximity and status equality of gossip targets and partners may be important variables in both the spread of gossip and the predominance of gossip's social functions within a given group. An advantage of the type of data collected in a network study is that the ties reported by individuals, although subjective with regard to the 


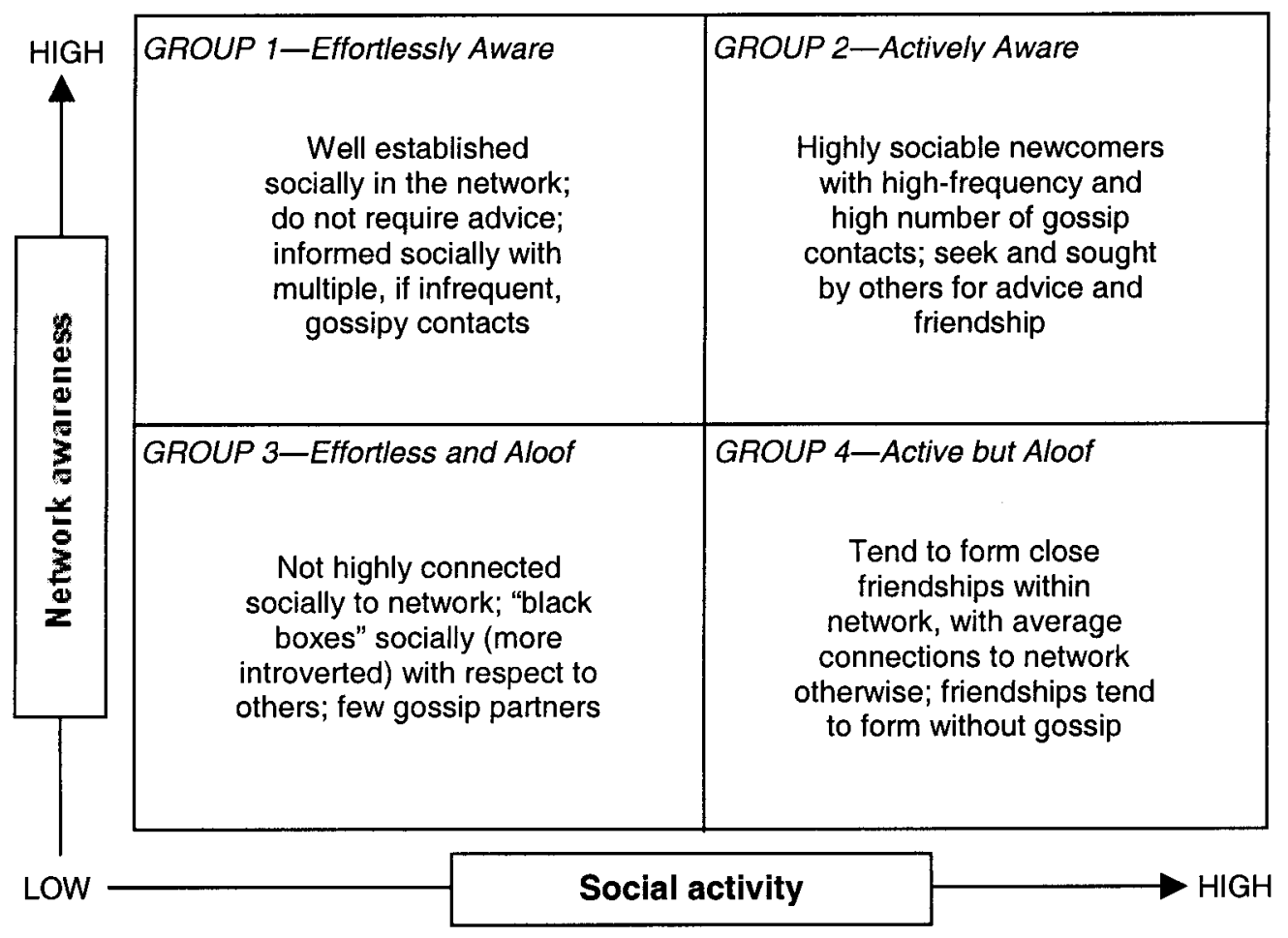

Figure 2. Four-group typology of gossipers.

respondent, are objective with regard to peers. Thus, certain social response bias problems associated with gossip self-reports may be overcome.

\section{Concluding Remarks}

As with stereotypes, persuasion, conformity, group dynamics, and other important areas of psychology, there are wide real-world implications for a better understanding of gossiping behavior within both the research and the general communities. And yet, gossip is relatively unfamiliar terrain in psychology. Few empirical data exist; only a limited number of experimental studies have been brought to bear on the topic. The general moral ambivalence toward gossip and the instrumental ambiguities involved call out for serious sociocognitive and psychophysiological explanations of how it is generated, perceived, processed, and used.

This review has shown that gossip is a heterogeneous phenomenon in content, forms, and functions. It may be manifested differently across the life span. It may idly fill hours of the day, passing practically unnoticed, or it may be motivationally generated or consumed (consciously or not) to alter internal states and achieve socially important external goals. As a general psychological strategy, people passively and actively use gossip to determine their view of the world and to convey it meaningfully to others. To no small extent, we learn how to behave, think, and communicate from and with gossip. For these reasons, it has the potential to create collegiality and understanding as well as inequality and conflict along gossip lines between and within social groups.

From the researcher's perspective, the complexities of gossip may be unsatisfying and problematic. But, of course, they are also challenges and opportunities for fecund and exciting inquiry. Strengthening the theory, methods, and instruments in this area will better inform the way we-managers, administrators, parents, teachers, peers, and colleagues-view this ubiquitous and fascinating behavior in context. 


\section{References}

Abrahams, R. D. (1970). A performance-centered approach to gossip. Man, 5, 290-301.

Adolphs, R., \& Damasio, A. R. (2000). Neurobiology of emotion at a systems level. In J. C. Borod (Ed.), The neuropsychology of emotion (pp. 194-213). New York: Oxford University Press.

Ayim, M. (1994). Knowledge through the grapevine: Gossip as inquiry. In R. F. Goodman \& A. BenZe'ev (Eds.), Good gossip (pp. 85-99). Lawrence: University Press of Kansas.

Barkow, J. H. (1992). Beneath new culture is old psychology: Gossip and social stratification. In J. H. Barkow, L. Cosmides, \& J. Tooby (Eds.), The adapted mind (pp. 627-637). Oxford, England: Oxford University Press.

Baumeister, R. F., Zhang, L., \& Vohs, K. D. (2004). Gossip as cultural learning. Review of General Psychology, 8, 111-121.

Ben-Ze'ev, A. (1994). The vindication of gossip. In R. F. Goodman \& A. Ben-Ze'ev (Eds.), Good gossip (pp. 11-24). Lawrence: University Press of Kansas.

Bergmann, J. R. (1993). Discreet indiscretions: The social organization of gossip. New York: Aldine de Gruyter.

Bernstein, L. M. (1984). Ko e lau pe (it's just talk): Ambiguity and informal social control in a Tongan village. Dissertation Abstracts International, 45(3A), 877-878.

Besnier, N. (1989). Information withholding as a manipulative and collusive strategy in Nukulaelae gossip. Language in Society, 18, 315-341.

Blau, P. M. (1964). Exchange and power in social life. New York: Wiley.

Blumberg, H. H. (1972). Communication of interpersonal evaluations. Journal of Personality and Social Psychology, 23, 157-162.

Bok, S. (1983). Secrets: On the ethics of concealment and revelation. New York: Pantheon Books.

Brown, E. B. (1990). Motley moments: Soap operas, carnival, gossip and the power of the utterance. In M. E. Brown (Ed.), Television and women's culture: The politics of the popular (pp. 183-198). London: Sage.

Brown, G. W. (1985). Joining two social institutions to counter rural Alaskan child abuse. Child Abuse and Neglect, 9, 383-388.

Burt, R. S., \& Knez, M. (1995). Kinds of third-party effects on trust. Rationality and Society, 7, 255292.

Coates, J. (1988). Gossip revisited: Language in allfemale groups. In J. Coates \& D. Cameron (Eds.), Women in their speech communities: New perspectives on language and sex (pp. 94-122). London: Longman.
Colson, E. (1953). The Makah Indians. Manchester, England: Manchester University Press.

Cox, B. A. (1970). What is Hopi gossip about? Information management and Hopi factions. Man, 5, 88-98.

Crampton, S. M., Hodge, J. W., \& Mishra, J. M. (1998). The informal communication network: Factors influencing grapevine activity. Public Personnel Management, 27, 569-584.

Damasio, A. R. (2000). A neurobiology for consciousness. In T. Metzinger (Ed.), Neural correlates of consciousness: Empirical and conceptual questions (pp. 111-120). Cambridge, MA: MIT Press.

Damasio, A. R. (2001). Emotion and the human brain. In A. R. Damasio, A. Harrington, J. Kagan, B. S. McEwen, H. Moss, \& R. Shaikh (Eds.), Unity of knowledge: The convergence of natural and human science (Vol. 935, pp. 101-106). New York: New York Academy of Sciences.

Derlega, V. J., \& Chaikin, A. L. (1977). Privacy and self-disclosure in social relationships. Journal of Social Issues, 33, 102-115.

Dunbar, R. I. M. (1992). Why gossip is good for you. New Scientist, 136, 28-31.

Dunbar, R. I. M. (1993a). Coevolution of neocortical size, group size and language in humans. Behavioral and Brain Sciences, 16, 681-694.

Dunbar, R. I. M. (1993b). On the origins of language: A history of constraints and windows of opportunity. Behavioral and Brain Sciences, 16, 721-735.

Dunbar, R. I. M. (1994). Grooming, gossip, and the evolution of language. London: Faber \& Faber.

Dunbar, R. I. M. (2004). Gossip in evolutionary perspective. Review of General Psychology, 8, $100-110$.

Dunbar, R. I. M., Marriott, A., \& Duncan, N. D. C. (1997). Human conversational behavior. Human Nature, 8, 231-246.

Eckert, P. (1990). Cooperative competition in adolescent "girl talk." Discourse Processes, 13, 91122.

Eder, D., \& Enke, J. L. (1991). The structure of gossip: Opportunities and constraints on collective expression among adolescents. American Sociological Review, 56, 494-508.

Eggins, S., \& Slade, D. (1997). Analyzing casual conversation. London: Cassell.

Elias, N., \& Scotson, J. L. (1965). The established and the outsiders. London: Frank Cass.

Emler, N. (1990). A social psychology of reputation. European Review of Social Psychology, 1, 171193.

Emler, N. (1994). Gossip, reputation and social adaption. In R. F. Goodman \& A. Ben-Ze'ev (Eds.), Good gossip (pp. 119-140). Lawrence: University Press of Kansas. 
Enquist, M., \& Leimar, O. (1993). The evolution of cooperation in mobile organisms. Animal Behaviour, 45, 747-757.

Fine, G. A., \& Rosnow, R. L. (1978). Gossip, gossipers, gossiping. Personality and Social Psychology Bulletin, 4, 161-168.

Foa, U. G. (1971). Interpersonal and economic resources. Science, 171, 345-351.

Foster, E. K. (2003). Researching gossip with social network analysis. Unpublished doctoral dissertation, Temple University, Philadelphia, PA.

Gelles, E. B. (1989). Gossip: An eighteenth-century case. Journal of Social History, 22, 667-683.

Gilbert, D. T., Fiske, S. T., \& Lindzey, G. (Eds.). (1998). The handbook of social psychology (4th ed., Vols. 1 \& 2). New York: McGraw-Hill.

Gilmore, D. (1978). Varieties of gossip in a Spanish rural community. Ethnology, 17, 89-99.

Gluckman, M. (1963). Gossip and scandal. Current Anthropology, 4, 307-316.

Goffman, E. (1959). The presentation of self in everyday life. New York: Doubleday.

Goodwin, M. H. (1982). "Instigating": Storytelling as a social process. American Ethnologist, 9, 799819.

Gottman, J., \& Mettetal, G. (1986). Speculations about social and affective development: Friendship and acquaintanceship through adolescence. In J. Gottman \& J. Parker (Eds.), Conversations of friends: Speculations on affective development (pp. 192-237). New York: Cambridge University Press.

Handelman, D. (1973). Gossip in encounters: The transmission of information in a bounded social setting. Man, 8, 210-227.

Hannerz, U. (1967). Gossip networks and culture in a Black American ghetto. Ethnos, 32, 35-59.

Harrington, C. L., \& Bielby, D. D. (1995). Where did you hear that? Technology and the social organization of gossip. Sociological Quarterly, 36, 607628.

Haviland, J. B. (1977). Gossip as competition in Zinacantan. Journal of Communication, 27, 186191.

Hecht, J. J. (1956). The domestic servant class in eighteenth-century England. London: Routledge \& Kegan Paul.

Homans, G. C. (1950). The human group. New York: Harcourt, Brace.

Hotchkiss, J. C. (1962, November). Children errandrunners: Their roles in the social life of a small Mexican community. Paper presented at the annual meeting of the American Anthropological Association, Chicago.

Jaeger, M. E., Skleder, A. A., Rind, B., \& Rosnow, R. L. (1994). Gossip, gossipers, gossipees. In R. F. Goodman \& A. Ben-Ze'ev (Eds.), Good gossip (pp. 154-168). Lawrence: University Press of Kansas.

Jones, D. (1980). Gossip: Notes on women's oral culture. In C. Kramarae (Ed.), The voices and words of women and men (pp. 193-198). Oxford, England: Pergamon Press.

Kurland, N. B., \& Pelled, L. H. (2000). Passing the word: Toward a model of gossip and power in the workplace. Academy of Management Review, 25, 428-438.

Kuttler, A. F., Parker, J. G., \& La Greca, A. M. (2002). Developmental and gender differences in preadolescents' judgments of the veracity of gossip. Merrill-Palmer Quarterly, 48, 105-132.

Leaper, C., \& Holliday, H. (1995). Gossip in samegender and cross-gender friends' conversations. Personal Relationships, 2, 237-246.

Levin, J., \& Arluke, A. (1985). An exploratory analysis of sex differences in gossip. Sex Roles, 12, 281-286.

Levin, J., \& Arluke, A. (1987). Gossip: The inside scoop. New York: Plenum.

Lindzey, G., \& Aronson, E. (Eds.). (1970). The handbook of social psychology (2nd ed., Vols. 1-5). Reading, MA: Addison-Wesley.

Lindzey, G., \& Aronson, E. (Eds.). (1985). The handbook of social psychology (3rd ed., Vols. 1 \& 2). New York: Random House.

Loudon, J. (1961). Kinship and crisis in South Wales. British Journal of Sociology, 12, 333-350.

Machiavelli, N. (1995). The prince and other political writings. London: Everyman. (Original work published 1516)

McCormick, N. B., \& McCormick, J. W. (1992). Computer friends and foes: Content of undergraduates' electronic mail. Computers and Human Behaviour, 8, 379-405.

Medini, G., \& Rosenberg, E. H. (1976). Gossip and psychotherapy. American Journal of Psychotherapy, 30, 452-462.

Mettetal, G. W. (1982). The conversations of female friends at three ages: The importance of fantasy, gossip, and self-disclosure. Unpublished doctoral dissertation, University of Illinois, Urbana.

Moreno, J. L. (1993). Who shall survive?: Foundations of sociometry, group psychotherapy and sociodrama. McLean, VA: American Society of Group Psychotherapy and Psychodrama.

Nevo, O., Nevo, B., \& Derech-Zehavi, A. (1993). The development of the tendency to gossip questionnaire: Construct and concurrent validation for a sample of Israeli college students. Educational and Psychological Measurement, 53, 973-981.

Nicolopoulou, A. (1997). Worldmaking and identity formation in children's narrative play-acting. In B. Cox \& C. Lightfoot (Eds.), Sociogenic perspectives in internalization (pp. 157-187). Hillsdale, NJ: Erlbaum. 
Noon, M., \& Delbridge, R. (1993). News from behind my hand: Gossip in organizations. Organization Studies, 14, 23-36.

Paine, R. (1967). What is gossip about? An alternate hypothesis. Man, 2, 278-285.

Paine, R. (1970). Informal communication and information-management. Canadian Review of Sociology and Anthropology, 7, 172-188.

Parsons, T. (1960). Structure and process in modern societies. Glencoe, IL: Free Press.

Planalp, S. (1993). Friends' and acquaintances' conversations II: Coded differences. Journal of Social and Personal Relationships, 10, 339-354.

Roberts, J. M. (1964). The self-management of cultures. In W. H. Goodenough (Ed.), Explorations in cultural anthropology (pp. 433-454). New York: McGraw-Hill.

Rosenbaum, J. B., \& Subrin, M. (1963). The psychology of gossip. Journal of the American Psychoanalytic Association, 11, 817-831.

Rosnow, R. L. (1977). Gossip and marketplace psychology. Journal of Communication, 27, 158-163.

Rosnow, R. L. (2001). Rumor and gossip in interpersonal interaction and beyond: A social exchange perspective. In R. M. Kowalski (Ed.), Behaving badly: Aversive behaviors in interpersonal relationships (pp. 203-232). Washington, DC: American Psychological Association.

Rosnow, R. L., \& Fine, G. A. (1976). Rumor and gossip: The social psychology of hearsay. New York: Elsevier.

Roy, D. F. (1958). Banana time: Job satisfaction and informal interaction. Human Organization, 18, $158-168$.

Rysman, A. (1977). How the "gossip" became a woman. Journal of Communication, 27, 176-180.
Sabini, J. P., \& Silver, M. (1978). Moral reproach and moral action. Journal for the Theory of Social Behaviour, 8, 103-123.

Schoeman, F. (1994). Gossip and privacy. In R. F. Goodman \& A. Ben-Ze'ev (Eds.), Good gossip (pp. 72-82). Lawrence: University Press of Kansas.

Slade, D. (1997). Stories and gossip in English: The macro-structure of casual talk. Prospect, 12, 4371.

Spacks, P. M. (1982). In praise of gossip. Hudson Review, 35, 19-38.

Stirling, R. B. (1956). Some psychological mechanisms operative in gossip. Social Forces, 34, 262 267.

Suls, J. M. (1977). Gossip as social comparison. Journal of Communication, 27, 164-168.

Szwed, J. F. (1966). Gossip, drinking, and social control: Consensus and communication in a Newfoundland parish. Ethnology, 5, 434-441.

Tannen, D. (1990). You just don't understand: Women and men in conversation. New York: Morrow.

Wert, S. R., \& Salovey, P. (2004). A social comparison account of gossip. Review of General Psychology, 8, 122-137.

Wilson, D. S., Wilczynski, C., Wells, A., \& Weiser, L. (2000). Gossip and other aspects of language as group-level adaptations. In C. Heyes \& L. Huber (Eds.), The evolution of cognition (pp. 347-365). Cambridge, MA: MIT Press.

Wilson, P. (1974). Filcher of good names: An enquiry into anthropology and gossip. Man, 9, 93102.

Yerkovich, S. (1977). Gossip as a way of speaking. Journal of Communication, 26, 192-196. 


\section{Appendix}

\section{Gossip Functions Questionnaire}

The Gossip Functions Questionnaire consists of 24 statements, 6 for each subscale. They are rated from 1 (strongly disagree) to 5 (strongly agree). Alpha internal-consistency reliabilities over three administrations $(N=110)$ are as follows: information, .80; friendship, .81; influence, .64; and entertainment, .80. The test-retest reliability for the entire scale is .64 (mean days to retest $=29, S D=16.8$ ). A formatted version, along with a spreadsheet that totals the scores with reversals, is available from the author.

\section{Information}

1. Generally, I try to figure out what is going on in the lives of people around me.

2. For me, informal chatting is unimportant for purposes of general information gathering.

3. Listening to people's opinions of others helps me better judge aspects of my own life.

4. When something personal happens to other people I know, if it doesn't directly affect me, I don't care to know about it.

5. I like to know what is going on with people, that is, who is dating whom, who is getting a new job, what classes people have had, and such.

6 . For me, gossiping with others is not a very good way to get useful information.

\section{Friendship}

1. Talking about the personal lives of other people makes me feel in touch with my social circle.

2. I believe that close friends can easily get personal information from each other about other people.

3. After I become friends with someone, I generally start to hear more about the personal issues of others from them.
4. With good friends, I tend to share information I've heard about others.

5. Some of my friendships were formed in part by talking about some third person.

6. I'm bored by spending time with my friends just talking about mutual friends.

\section{Influence}

1. When someone does something inappropriate, I think others should know so the person will be less likely to do it again.

2. Hearing stories about others could help me avoid saying or doing the wrong thing.

3. When I hear gossip, it can change my behavior toward someone, for better or for worse.

4. It's fair to say that gossip tells us what to do, that is, how to behave in a lot of situations.

5. Though people will "talk" about others, this is not effective at bringing people into line.

6. It is OK to tell a new person in my circle what it was about someone who is gone that no one liked.

\section{Entertainment}

1. I don't have to know whether talk about people is true or not to enjoy the activity.

2. I like to gossip at times.

3. For me, there's nothing enjoyable about passing on personal information.

4. I can't understand why people get so much pleasure out of gossiping.

5. I could spend hours listening to stories about the lives of the people I know.

6 . I can't stand being around people who talk about other people behind their backs.

Received June 2, 2003

Accepted July 1, 2003 